\title{
New Effective Korean Character Keypads using Dragging on Smart Phones
}

\author{
Jaeyoung $\mathrm{Choi}^{\dagger} \cdot$ Sanggul $\mathrm{Lim}^{++} \cdot$ Woocheol Yang ${ }^{++}$
}

\begin{abstract}
Smart phones have been technologically advanced in many ways from basic cellular phones. However, most of all smart phone users in Korea still have been using the traditional Korean character keypads used in the basic cellular phones. It would be required to develop new keypads on smart phones with touch screen. In this paper, we extended the three standard Korean character keypads - Cheonjiin, Naragul, and SKY-Hangul - by adding dragging function on touch screen, then we compared writing speeds of the keypads based on the number of touching buttons and moving distance of the finger while writing a sentence. In addition, we proposed two new Korean keypads - 's-Gana' and 's-Bada,' which are more suitable on smart phones. $s$-Gana assigned 7 representative consonants and 5 representative vowels in order on the $4 \times 3 \mathrm{keypad}$, and $s$-Bada assigned consonants and vowels by considering their frequency of use. $s^{-}$Gana and $s^{-B a d a}$ keypads showed $3 \sim 19 \%$ and $9 \sim 24 \%$ of performance improvement, respectively, compared with the standard Korean keypads. Finally, we set up 5 requisites of SELF-T in order to evaluate the usability of Korean character keypads in smart phones, then we compared the keypads using the requisites.
\end{abstract}

Keywords : Korean Keypad, Smart Phone, Cheonjiin, Naragul, SKY-Hangul, s-Keypad, $s$-Bada

\section{스마트폰에서 끌기 기능을 이용한 효과적인 한글 문자 자판}

\author{
최 재 영 $^{\dagger}$. 임 상 글 ${ }^{\dagger+}$. 양 우 철 ${ }^{\dagger+}$
}

\section{요 약}

주로 통화 기능을 제공하던 일반폰과 비교하여 스마트폰은 여러 면에서 기술적으로 진보된 기기이다. 하지만 사용자들은 일반폰에서 사용하 던 한글 문자 자판들을 여전히 스마트폰에서 사용하고 있다. 터치스크린이 있는 스마트폰에서 보다 효과적으로 한글을 입력할 수 있는 자판이 요구되고 있다. 먼저 본 논문에서는 표준 한글 문자 자판인 천지인, 나랏글, 그리고 SKY한글에 끌기 기능을 추가하여 확장하였으며, 터치 횟수 와 손가락이 움직이는 거리를 기준으로 기존의 한글 자판들과 입력 속도를 비교하여 성능이 향상되는 것을 확인하였다. 또한 추가적으로 스마 트폰에 적합한 ' $s$-가나'와 's-바다' 한글 자판들을 제안하였다. $s$-가나 자판에서는 7 개의 대표 자음과 5 개의 대표 모음들을 순서대로 배치하였으 며, $s^{-}$바다 자판에서는 자음과 모음들을 사용빈도에 따라 많이 사용되는 자판들을 서로 가깝게 배치하였다. 표준 한글 자판들과 비교하여, $s^{-}$가 나 자판은 $319 \%, s$-바다 자판은 $924 \%$ 의 성능이 개선되었다. 마지막으로 본 논문에서는 스마트폰에서 한글 자판들의 사용성을 평가하기 위하 여 SELF-T의 5가지 요소들을 설정하였으며, 이 요소들을 기준으로 한글 자판들을 비교하였다.

키워드 : 한글 자판, 스마트폰, 천지인, 나랏글, SKY한글, $s$-키패드, $s$-바다

\section{1. 서 론}

2009년 11월에 애플의 '아이폰 3GS'를 시작으로 2010년 2월 안드로이드 기반의 '모토로이'가 출시되면서 본격적으로 국내에 스마트폰이 보급되었다. 아이폰과 모토로이의 출시

\footnotetext{
※ 본 연구는 미래창조과학부 및 정보통신산업진흥원의 대학 IT연구센터 육성지원사업의 연구결과로 수행되었음(NIPA-2013-H0301-13-2006).

† 종신회원 : 숭실대학교 컴퓨터학부 교수

†† 준 회 원 : 숭실대학교 컴퓨터학부 학사과정

논문접수: 2013년 1월 28일

수 정 일 : 1 차 2013년 2월 26일

심사완료 : 2013년 3월 4일

* Corresponding Author: Jaeyoung Choi(choi@ssu.ac.kr
}

를 기점으로 본격적으로 늘기 시작한 국내 스마트폰 사용 자 수는 2011년 3월에 1000만 명을 기록한데 이어, 2012년 8 월에 3000 만 명을 돌파하는 등 엄청난 속도로 스마트폰이 보급되고 있다[1].

스마트폰은 일반폰 (피쳐폰이라고도 함)과 $\mathrm{PDA}$ 가 결합된 정보기기로써, 기본적인 통화 기능을 비롯하여 인터넷 검색, 일정관리, 정보처리와 같은 다양한 기능을 제공한다. 또한 스마트폰에서는 앱 마켓을 통해 다양한 응용 프로그램들이 제공되며, 카카오톡과 트위터 같은 SNS를 기반으로 하는 새로운 서비스들이 등장하였다. 이러한 서비스들이 보편화 되면서 스마트폰에서는 사용자들이 문자 입력을 더욱 많이 
사용하게 되었다.

국내 일반폰에서 대표적으로 사용하는 한글 문자 자판은 천지인, 나랏글, SKY한글이며, 최근에는 Qwerty 자판의 사 용률이 증가하고 있는 추세이다. 방송통신위원회에 따르면 2010년 10월을 기준으로 천지인이 $55 \%$, 나랏글이 $20 \%$, 그 리고 SKY한글이 $14 \%$ 의 점유율을 차지하고 있다. 이러한 점유율을 바탕으로, 2011년 6월에 일반폰에서는 천지인으로 표준화되었으며[2], 스마트폰에서는 천지인과 나랏글, SKY 한글 모두 한글 문자 자판의 표준으로 제정되었다[3]. 한글 은 자음과 모음을 조합하여 글자를 입력해야 하는 특성 때 문에, 3 가지 한글 자판들 모두 10 개 혹은 12 개 버튼에 하나 이상의 자음 및 모음들을 배치하여야 한다. 이러한 제약으 로 인하여 3 가지 한글 표준 자판들은 같은 버튼을 여러 번 의 눌러서 원하는 자음 혹은 모음을 선택하는 방식을 요구 하며, 물리적인 버튼을 제공하지 않는 터치스크린 기반의 스마트폰에서 잦은 오타를 유발한다. 또한 Qwerty 자판은 한정된 공간에 많은 버튼들이 있기 때문에 이중 입력과 탈 자가 자주 발생한다.

Nielsen과 Mack는 기기에서의 사용성 평가기준으로 효율성 (Efficiency), 학습성 (Learn-ability), 기억성 (Memorability), 오류성 (Errors), 만족성 (Satisfaction)을 제시하였다[4]. 그 러나 일반폰에서의 한글 문자 자판에 대한 연구는 비교 평 가기준으로 입력 속도에 국한되는 경향이 있다[5]. 본 논문 에서는 스마트폰에서 한글 문자 자판들을 비교 평가하기 위 하여 4 가지 필수 요소와 1 가지 권장 요소를 설정하였고, 이 를 간단히 SELF-T로 부르기로 한다.

- Simplicity - 단순하고 직관적이어 사용하기 쉬워야 하 며, 모든 문자들을 같은 방식으로 입력할 수 있어야 한다.

- Errors - 문자를 입력하는데 오류가 적게 발생하여야 하 며, 오류가 발생하더라도 수정이 용이하여야 한다.

- Learnability - 배우기가 용이하여 사용자들이 학습하는 데 거부감이 없어야 한다.

- Fast - 사용자의 문자 입력 속도가 빨라야 한다.

- up-to-date Technology (권장 요소) - 최신의 기술이 적 용되어 보다 효과적인 입력이 가능하여야 한다.

휴대폰의 하드웨어 및 소프트웨어 기술이 발전하면서, 그 에 따른 최신의 기술 (up-to-date Technology)을 적용하여 4 가지 필수 요소들(SELF)을 향상시킬 수 있다면 사용성이 더욱 좋아질 것이다. 터치스크린 기반의 스마트폰은 끌기 (Dragging)라는 새로운 입력 기능을 제공한다. 이 기술을 적용하면 한글 문자 입력이 더 단순해지고, 오류가 적어지 며, 배우기 쉽고, 입력 속도도 빨라지는 등, SELF의 4 가지 요소들을 더욱 만족시킬 수 있다.

최근에는 끌기 기술을 적용하여 밀기글과 딩굴 등 새로운 한글 문자 자판들이 개발되었다. 밀기글과 딩굴은 한글의 창 제 원리에 끌기 기능을 적용하여 보다 빠르고 효율적으로, 그 리고 짧은 시간에 많은 양의 한글을 입력할 수 있다. 하지만 밀기글과 딩굴은 기존의 $4 \times 3$ 의 한글 자판과 다른 배치를 가지
고 있으며, 복모음 입력이 복잡하고 직관성이 떨어지기 때문 에 새로운 입력 방식을 익히기까지 시간과 노력이 필요하다.

본 논문에서는 먼저 표준 한글 문자 자판인 천지인, 나랏 글, SKY한글에 끌기 기능을 추가하여 각각의 자판을 확장 하였다. 끌기 기능이 추가된 자판들을 각각 ' $\mathrm{S}^{-}$-천지인', ' $\mathrm{s}$ 나랏글', 's-SKY'라고 한다. 기존 3 개의 한글 자판과 확장된 3 개의 $S$-자판들을 비교하기 위하여, 한글 예문을 입력하기 위한 터치횟수와 손가락이 움직이는 거리의 합으로 입력 속 도를 측정하였다. 끌기 기능이 추가된 $s$-자판들은 기존의 자판들과 비교하여 각각 $6.0^{\sim} 7.6 \%, 15.4 \% 19.2 \%, 0.72 .9 \%$ 의 성능이 향상되는 것을 확인하였다.

또한 본 논문에서는 스마트폰에서 사용하기에 적합한 새 로운 2 개의 한글 문자 자판을 제안한다. ' $\mathrm{S}$-가나' 자판은 기 본적으로 7 개의 대표 자음과 5 개의 대표 모음을 $4 \times 3$ 의 버튼 에 배치하였으며, 19 개의 모든 자음과 21 개의 모든 모음을 끌기를 이용하여 사용자가 바로 선택할 수 있도록 하였다. 사용자들이 많이 사용하는 자음과 모음을 서로 가까이 배치 하면 손가락이 움직이는 거리가 줄게 되고 입력 속도가 빨 라지게 된다. 이를 위하여 's-바다' 한글 자판은 자음과 모 음의 사용빈도를 분석하여, 많이 사용하는 자음과 모음 버 튼들을 서로 가까이 배치하였다.

새롭게 제안된 $s^{-}$가나와 $s^{-}$바다 자판을 끌기 기능을 적 용하여 확장된 $s^{-}$천지인, $s^{-}$나랏글, $s^{-} \mathrm{SKY}$ 자판들과 입력 속도를 비교하였다. $s^{-}$가나 자판은 $s^{-}$천지인과 $s^{-} \mathrm{SKY}$ 자판 과 비교하여 각각 $14 \%$ 와 $3 \%$ 의 성능 향상을 보였지만, $s^{-}$나 랏글 자판과 비교해서는 오히려 성능이 저하되었다. $S^{-}$바다 자판은 $s^{-}$천지인과 $s^{-} \mathrm{SKY}$ 자판에서 각각 $22 \%$ 와 $12 \%, s^{-}$ 나랏글 자판에서도 3 $7 \%$ 의 성능 향상을 보였다. 끌기 기능 이 없는 기존의 천지인과 나랏글, $\mathrm{SKY}$ 한글 자판과 비교하 면, $s^{-}$가나 자판은 $319 \%$ 의 성능이, 그리고 $s^{-}$바다 자판은 $924 \%$ 의 성능이 개선되었다. 마지막으로 SELF-T의 5가지 요소들을 가지고 천지인, 나랏글, $\mathrm{SKY}$ 한글 자판들과 함께 밀기글과 딩굴, 그리고 $s^{-}$가나와 $s^{-}$바다 자판들의 사용성을 비교 평가하였다.

\section{2. 기존의 한글 문자 자판}

스마트폰에서는 천지인, 나랏글, SKY한글의 한글 문자 자판들이 많이 사용되고 있으며, 최근에는 Qwerty 자판의 점유율도 점차 늘어나고 있다. 스마트폰용으로 개발된 밀기 글과 딩굴은 한글 문자를 입력하기 위해 새롭게 개발된 자 판 중에서 가장 널리 알려진 자판이다. 이 장에서는 위에서 설명한 6 개 한글 자판들의 특징들을 간략히 알아본다.

\section{1 천지인}

삼성전자 휴대폰에서 사용하는 자판으로, 한글 창제의 모 음 구성 원리를 응용하여 최초 사용시에 편리하다. 천지인 $(\cdot /-/ /) 3$ 개의 요소를 조합하여 모음을 만들어내는 단순 한 구조로 배우기 쉽다. Fig. 1에서 보듯이 7 개 버튼 각각에 
2 개의 기본 자음들을 배치하였으며, 원하는 자음을 입력하 기 위하여 버튼을 여러 번 터치해야 한다. 다만 모음을 입 력할 경우에 모음을 조합해야 하므로 입력 횟수가 많아지며, 모음이 가로로 배열되어 양손을 사용할 때 불편하다. 또한 같은 자음을 연속으로 입력해야 할 경우에, 커서의 이동을 기다리거나 '\#’ 버튼을 입력해야 한다.

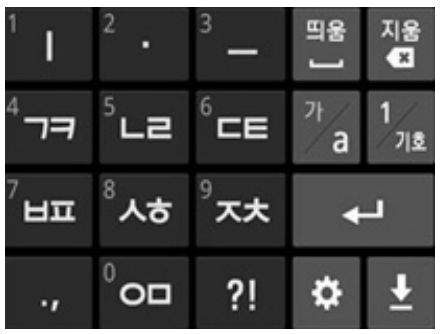

Fig. 1. Cheonjiin Keypad

\section{2 나랏글}

$\mathrm{LG}$ 전자에서 개발한 한글 자판으로 자음을 6 개의 버튼에, 모음을 4 개의 버튼에 배치하였다. '획추가 $(*)$ ' 버튼과 '쌍자 음(\#) 버튼의 조합을 통하여 모음과 자음을 입력할 수 있다. 천지인과 비교하여 버튼을 무르는 횟수가 적어서 속도가 빠 르며, 같은 자음을 연속으로 입력하기가 용이하다. 하지만 문자를 입력하면서 '획추가(*)' 버튼이나 '쌍자음(\#)' 버튼을 눌러야 하기 때문에 초기 학습이 어렵고 손가락의 이동 거 리가 길어지게 된다.

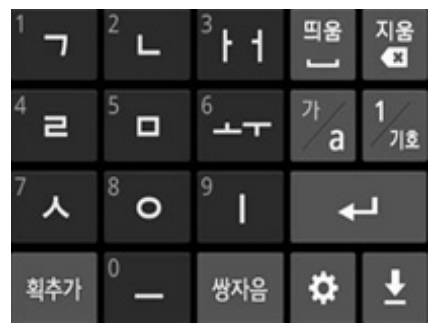

Fig. 2. Naragul Keypad

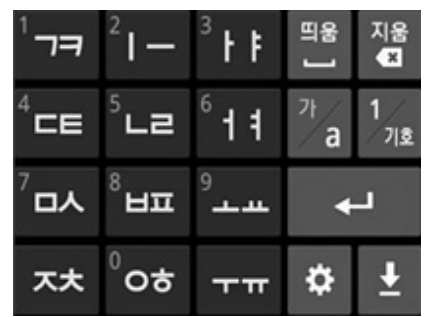

Fig. 3. SKY Hangul Keypad

\subsection{SKY한글}

팬택에서 개발한 한글 자판으로, 7 개의 자음과 5 개의 모음 을 12 개 버튼에 배치하였으며, 많이 사용되는 자음인 'ㄴ'과 'O'을 가운데 열에 배치하였다. SKY한글은 모든 기본 자음 과 모음을 보면서 입력할 수 있으므로 다른 자판들과 비교하
여 비교적 한글 입력이 쉽다. 하지만 복모음 조합이 용이하 지 않고, 쌍자음을 입력할 때 추가 동작을 필요로 한다.

\subsection{Qwerty}

외국기업에서 제조한 대부분의 스마트폰에서 사용하는 방 식이다. $\mathrm{PC}$ 에서 사용하는 두벌식 한글 자판 배열을 그대로 적용하였다. $\mathrm{PC}$ 키보드에 익숙한 사용자들이 쉽게 적응할 수 있다. 자음과 모음이 양쪽으로 배치되어 있어서 양손으 로 입력하기가 용이하지만, 한손으로 입력하려면 손가락의 이동거리가 길어지게 되어 다른 자판들과 비교하여 입력 속 도가 느리다. 좁은 화면에 모든 버튼들을 배치해야 하므로 화면의 크기가 작은 스마트폰에서는 버튼들의 크기가 작아 서 이중 입력과 오타의 발생 빈도가 높다.

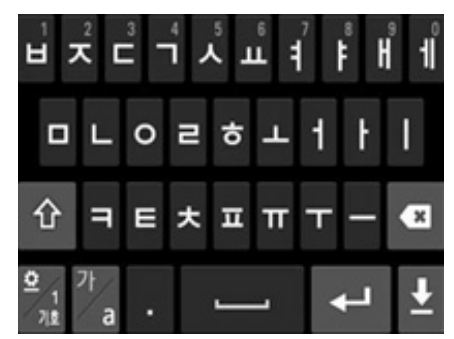

Fig. 4. Qwerty Hangul Keypad

\section{5 밀기글}

밀기글[6]은 끌기 기반의 한글 자판으로, $3 \times 5$ 의 15 개 버 튼으로 구성된다. 한 가운데에 모음 ' 1 '와 '- '버튼을, 나머 지 버튼에 14 개 자음을 순서대로 배치하였다. 자음 버튼을 터치하면 선택한 자음 버튼에 상하좌우로 '', 'T', 'ㄱ' ', ' ' 가 결합된 글자가 표시되며, 결합된 글자를 선택한 뒤에 손 을 떼지 않고 다음 자음으로 이동하면 종성까지 한 번에 입 력할 수 있다. 이러한 특징으로 밀기글은 가장 빠른 입력 속도를 보인다. 하지만 모음을 입력하는 과정은 직관성이 떨어지며, 특히 복모음의 입력이 불편하다. 완전히 다른 방 식이 적용되므로 사용자의 많은 학습시간이 요구된다.

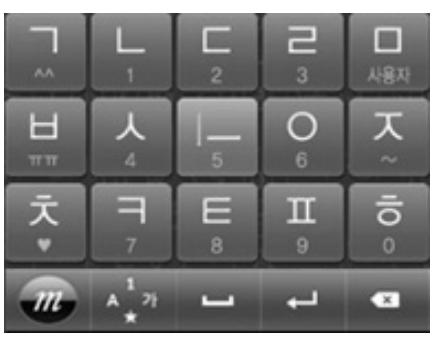

Fig. 5. Milgigul Keypad

\section{6 딩굴}

딩굴[7]은 끌기 기능을 적용한 자판들 중에서 가장 많이 사용되고 있다. $4 \times 3$ 의 배치를 가지며, 오른쪽 4 개 버튼에 모 음을, 나머지 8 개 버튼에 자음을 배치하였다. 버튼을 터치할 
경우, 상하좌우로 자음과 모음들이 표시되며 그중 한 방향 으로 끌기를 하면 그 위치에 있던 한글 문자가 입력된다. 자음의 배치는 기존의 한글 자판들과 큰 차이가 없지만, 모 음은 모양에 따라 분류되어 직관성이 떨어지는 편이다. 또 한 기존의 한글 자판들과 비교하여 자판 배열이 다르기 때 문에, 사용자가 익숙해지기 위한 학습시간이 필요하다.

\begin{tabular}{|c|c|c|c|}
\hline$=7$ & $=\stackrel{\pi}{\stackrel{\pi}{c}}=$ & -1 & $\underset{4 凶}{\otimes}$ \\
\hline$=\hat{己}$ & $=\ddot{\prime \prime}=$ & 1. & $+?$ \\
\hline $1 \hat{\imath}^{3} 3$ & ${ }_{4}{ }_{4} \mathrm{O}_{5}{ }_{5}$ & $-\|$ & $\therefore$ \\
\hline , 走. & $7 \frac{0}{6} 9$ & & । \\
\hline \begin{tabular}{l|l} 
S엄 & 한/영
\end{tabular} & 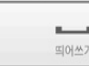 & 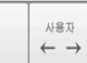 & 다음 \\
\hline
\end{tabular}

Fig. 6. Dinggul Keypad

\section{3. 끌기(Dragging) 기능을 추가한 개선된 표준 한 글 자판}

물리적 자판이 탑재된 일반폰은 대부분 $4 \times 3$ 의 12 개 버튼 을 사용하며, 같은 버튼을 여러 번 터치해야 원하는 문자를 입력할 수 있다. 그러나 스마트폰에서는 터치스크린의 버튼 을 누르고 있는 상태에서 화면의 상태를 변경하거나 제어할 수 있다. 이 장에서는 표준으로 제정된 3 개의 한글 자판들에 끌기기능을 적용시켜 개선하였으며, 각각 $S^{-}$천지인, $S^{-}$나랏 글, $S^{-} \mathrm{SKY}$ 라고 한다. 개선된 $S^{-}$자판들은 기존의 자판들과 호환성을 유지하면서 끌기 기능을 추가하였기 때문에, 사용 자가 손쉽게 사용할 수 있다. 짧게 터치하면 기본적으로 버 튼에 배치된 문자가 바로 입력되며, 터치하면 상하좌우로 선 택할 수 있는 문자들을 보여준다. 기존에는 하나의 문자를 선택하기 위하여 같은 버튼을 여러 번 터치해야 하였지만, 개선된 $S^{-}$자판에서는 손가락을 끌어서 그 문자를 선택하고, 그 문자 위에서 손가락을 떼면 해당 문자가 입력된다.

\section{1 개선된 한글 문자 자판 $-s$-자판}

$S^{-}$천지인 자판에서는, 자음은 기본적으로 가획되는 자음 (격음)을 좌우에, 쌍자음(경음)을 상하에 배치하였다. 모음에 서 '・'는 'I'와 '- '에 상하좌우로 가획되는 형태인 $\perp / T / H$ / 산으로 배치하며, 'I'에서는 ']'와 ㄴ/T T/ ㄱ/ / 를 붙여 서 발음했을 때 나는 소리를 기반으로 표/T/ㅋ//F를 배치하 였다. '- '는 좌우를 '기'로 상하로는 'ㄱ'에 '・'가 가획되는 형태인 '기'와 '기'를 배치하였다.

$S^{-}$나랏글 자판은 버튼의 상하좌우에 기존의 나랏글 자판 에서 '획추가(\#)'와 '쌍자음(*)' 버튼으로 만들 수 있었던 문 자들을 배치하며, $S^{-}$천지인 자판과 마찬가지로 좌우와 상하 에 각각 격음과 경음을 배치하였다.

마지막으로 $S^{-} \mathrm{SKY}$ 자판은 기존 $\mathrm{SKY}$ 한글에서 멀티탭 방 식으로 표시되는 문자들을 우측을 기준으로 반시계방향 순으 로 배치하였다. 3 가지 $S^{-}$자판의 문자 배치는 Fig. 7 과 같다.

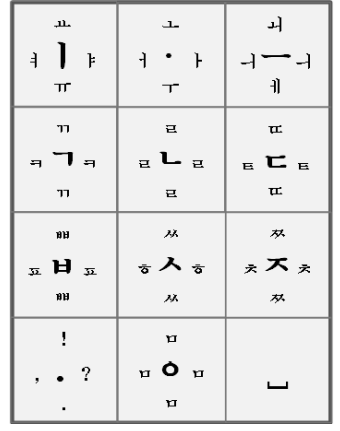

(a) s-Cheonjiin

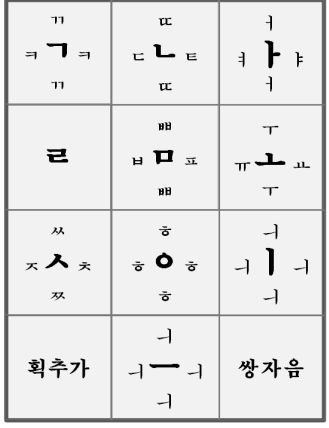

(b) s-Naragul

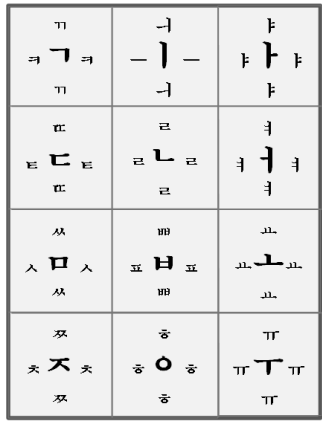

(c) $s-S K Y$
Fig. 7. s-Keypads modified from 3 standard Korean Keypads

\section{$3.2 s$-자판 비교}

본 실험에서는 각 자판에서 문장을 입력하면서 누르는 버 튼의 터치 횟수와 함께 움직이는 손가락의 이동거리를 비교 하였다. 터치 횟수는 자음 혹은 모음을 입력하기 위하여 버 튼을 누르는 총 횟수이며, 이동거리는 사용자가 하나의 버 튼을 터치하거나 끌기를 한 후에 그 다음 버튼을 선택하기 위해 손가락이 움직이는 거리를 모두 더한 값이다. 버튼 사 이의 이동거리는 상하좌우로 인접한 버튼 사이의 거리를 1 로 하고, 이를 바탕으로 버튼 간의 직선거리로 손가락의 이 동거리를 계산하였다. 터치횟수와 이동거리를 따로 계산하 였지만, 자판들의 비교를 단순화하기 위하여 손가락으로 버 튼을 한번 터치하는 시간과 손가락이 터치한 상태에서 버튼 크기만큼 움직이는 시간을 같다고 가정하고, 버튼의 터치 횟수와 손가락의 이동 거리를 더한 결과를 비교하였다. 예 를 들어 ' $\exists '$ 을 입력하려면, $S$-자판에서는 한번 터치하고 1 의 버튼 크기만큼 손가락을 움직여야 한다. 즉 손가락으로 'ㄱ' 버튼을 누르고 있는 상태에서 1의 거리를 움직이므로, 같은 버튼을 두번 터치하는 천지인 방식의 입력시간과 같다 고 가정하였다.

비교 실험을 위한 예문으로, Fig. 8에서 보듯이 애국가 1 절과 훈민정음 서문을 사용하였다. 애국가는 부드러운 음을 만들기 위하여, 주로 자음은 평음을 그리고 모음은 단모음 을 사용하고 있다. 애국가에서 자음은 경음이나 격음을, 모 음은 복모음과 같이 조합을 필요로 하는 문자가 상대적으로 적기 때문에, 예문으로 훈민정음 서문을 추가하여 함께 사 용하였다. 또한 본 실험에서는 $4 \times 3$ 의 12 개 버튼을 대상으로 
동해물과 백두산이 마르고 닳도록

하느님이 보우하사 우리나라 만세 무궁화 삼천리 화려강산

대한 사람 대한으로 길이 보전하세

(a) The first verse of Korean National Anthem

나랏말싸미 듕귁에 달아 문자와를 서로 사맛디 아니할세 이런 전차로 어린 백성이 니르고저 할빼이셔도

마참내 제 뜻을 능히펴지 못할 놈이 하니다.

내이를 어여삐 녀겨 새로 스물 여덟자를 맹가노니

사람마다 수비니겨 날로 쓰매 편아케 하고저 할 따라미니라

(b) Preface of Hunminjeongeum

Fig. 8. Korean sentences for experiments

하였으며, 추가적인 버튼을 고려하지 않았다. 띄어쓰기 및 줄바꿈을 위해서는 버튼들을 추가해서 사용하여야 하며, 이 추가된 버튼들의 위치에 따라 이동거리가 많이 달라지기 때 문이다. 이번 실험에서는 Fig. 8의 예문에서 띄어쓰기 및 줄 바꿈을 제외한 문자들만 입력한 결과를 비교하였다.

실험 예문을 기준으로 기존의 자판과 개선된 자판에서 실 험한 결과는 Fig. 9와 같다. 애국가에서는 최소 $2.9 \%$, 최대 $15.4 \%$ 의 성능이 향상되었으며, 훈민정음에서는 최소 $0.7 \%$, 최대 $19.2 \%$ 의 성능이 향상되었다.

천지인 자판에서는 $6 \%$ 정도의 성능이 향상되었다. 천 지인 자판에서는 $\cdot / / / 1$ 버튼을 여러 번 터치하여 모음을

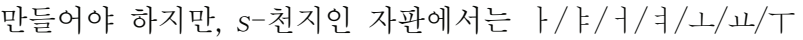
$/ \pi$ 의 모음을 끌기를 통해 바로 선택할 수 있어 터치 횟수 가 줄어들었다. 나랏글에서는 15 19\%의 성능이 향상되었다. 나랏글에서 기존의 '획추가(\#)'와 '쌍자음(*)' 버튼을 통해 자 음과 모음을 입력하던 과정을 $S^{-}$나랏글은 끌기 기능으로 손 쉽게 입력이 가능해지면서 터치횟수와 이동거리가 크게 감 소하였다. SKY한글 자판에서는 1 3\% 정도의 상대적으로 적은 성능 향상을 보였다. 이는 기존의 버튼을 여러 번 눌 러서 문자를 입력하는 방식을 단지 확장 버튼에 상하좌우로
배치시킨 문자들 중 하나를 선택하는 방식으로 바꾼 것이기 때문이다.

Fig. 9의 수치에서 보듯이, 천지인과 나랏글, SKY한글 자 판에서 모두 끌기 기능을 사용하여 성능이 향상된 것을 확 인할 수 있다. 또한 끌기 기능이 적용된 $S^{-}$자판에서는 터치 횟수가 감소되어 오자 및 탈자가 상대적으로 줄어드는 효과 가 있으며, 기존의 자판 배치와 조합을 그대로 가져오면서 끌기 기능을 추가하였기 때문에 사용자들이 손쉽게 사용할 수 있다.

\section{4. 새로운 한글 자판 $-s$-가나와 $s$-바다}

이 장에서는 스마트폰에 적합한 2 개의 새로운 $S^{-}$자판을 제안한다. 이미 사용자들은 $4 \times 3$ 의 12 개 버튼에 익숙해있으 므로, 12 개의 버튼에 자음과 모음을 배치하였다. 기본적으로 7 개의 대표 자음과 5 개의 대표 모음을 $4 \times 3$ 의 버튼에 배치하 였으며, ㄱ/ㄱ/l 모음을 자음의 오른쪽에, ㄴ/T 모음을 자 음의 아래쪽에 배치하여 사용자들의 직관성을 높였다. 또한 21 개의 모든 모음들을 사용자가 바로 선택하거나 조합할 수 있도록 하였다.

\section{$4.1 s$-가나 한글 자판}

Table 1 은 기본 자음 14 개와 경음 5 개의 분류를 보여주 고 있다[8]. 새로운 자판은 Table 1 과 같이 자음들을 각 음 의 성질에 따라 분류한 뒤, 비슷한 음을 가진 자음들을 하 나로 모아서 같은 버튼에 배치하였다. 폐쇄음에서 연구개음 인 ᄀᄀ(평음)/ 77 (경음)/ ㄱ(격음)을 묶고, 치조음인 ㄷ/ 드/트을, 그리고 양순음인 ㅂ/빠/프을 묶어서 각각 하나의 버튼에 배 치한다. 또한 파찰음인 ㅈ/ㅉㅈ/츠를 묶고, 같은 마찰음인 치 조음 싰ㅆㄱㅘ 후음 ㅎ을 묶어서 각각 하나의 버튼에 배치한 다. 마지막으로 유성음 중에서 치조음인 ㄴ/르을 묶고, 남은 비음인 $O / \square$ 을 묶어서 각각 동일한 버튼에 배치하도록 한 다. 위의 방식으로 7 개의 대표 자음으로 모든 자음들을 분 류하면 Table 2와 같다.

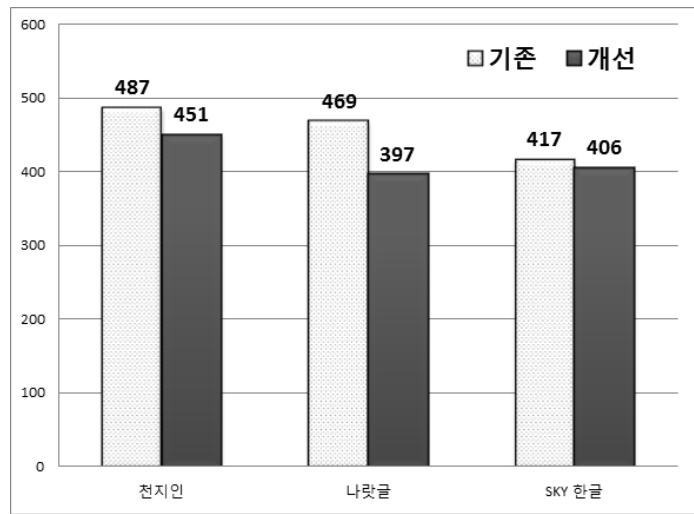

(a) Korean National Anthem

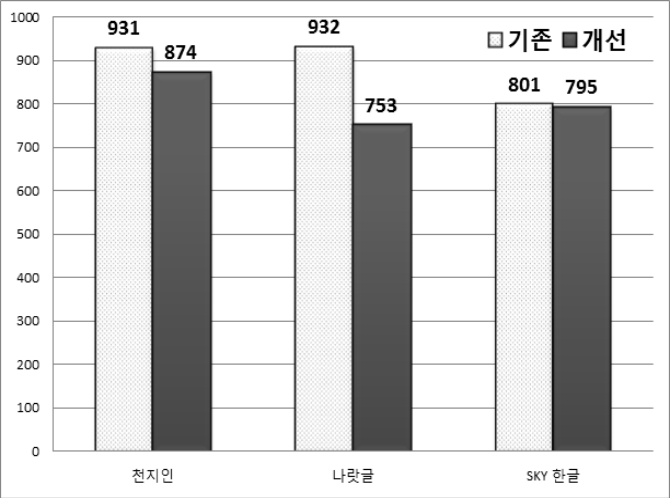

(b) Hunminjeongeum

Fig. 9. Performance Comparision of Korean Keypads 
Table 1. Categorization Table of Korean Consonants

\begin{tabular}{|c|c|c|c|c|c|c|}
\hline & & 양순음 & 치조음 & $\begin{array}{l}\text { 경구 } \\
\text { 개음 }\end{array}$ & $\begin{array}{l}\text { 연구 } \\
\text { 개음 }\end{array}$ & 성문음 \\
\hline \multirow{3}{*}{ 폐쇄음 } & 평음 & ㅂ & ᄃ & & 7 & \\
\hline & 경음 & 昰 & $\llbracket \llbracket$ & & 77 & \\
\hline & $\begin{array}{c}\text { 격음 } \\
\text { (유기음) }\end{array}$ & 프 & E & & $\Rightarrow$ & \\
\hline \multirow{2}{*}{ 마찰음 } & 평음 & & 人 & & & о \\
\hline & 경음 & & 从 & & & \\
\hline \multirow{3}{*}{ 파찰음 } & 평음 & & & 下 & & \\
\hline & 경음 & & & 不 & & \\
\hline & $\begin{array}{l}\text { 격음 } \\
\text { (유기음) }\end{array}$ & & & 天 & & \\
\hline 비음 & & 마 & ᄂ & & o & \\
\hline 유음 & & & ᄅ & & & \\
\hline
\end{tabular}

Table 2. Categorization for Consonants Placement on Keypad

\begin{tabular}{|c|c|}
\hline Representative Consonants & Assigned Consonants \\
\hline$\neg$ & $\neg / 77 / \neg$ \\
\hline ᄂ & ㄴ/ᄅ \\
\hline ᄃ & $ᄃ / \tau \tau / E$ \\
\hline ㅂ & ㅂ/비/표 \\
\hline 人 & ㅅ/从/ㅎㅎ \\
\hline 0 & О/口 \\
\hline 下 & ㅈ/자/ᄎ \\
\hline
\end{tabular}

한편 한글 모음은 천지인 자판처럼 $・ / / 1$ 버튼을 조합 하여 구성하거나, 나랏글 자판처럼 $1 / / / / 1 / T / / / 1$ 를 기본 요소로 하여 조합할 수 있다. 모음은 천지인 자판처럼 기본 요소를 단순화할수록 적은 수의 버튼으로도 모든 모음을 입 력할 수 있지만, 조합 과정으로 인하여 버튼을 누르는 횟수 가 많아진다. 모음 버튼들의 배치를 결정하기 위해 한글에 서 사용되는 21 개의 모음들을 비슷한 계열끼리 묶어서 분류 하면 Table 3과 같다.

Table 3. Representative Vowels with their Assigned Vowels

\begin{tabular}{|c|c|}
\hline Representative Vowels & Assigned Vowels \\
\hline r & ト/H/作/月 \\
\hline - & †/ㄱ/月/켸 \\
\hline$\perp$ & 니/교/나/개/기 \\
\hline$T$ & T/T/ㅓㅓ/께/Tㅈ \\
\hline 1 & $1 /-1 / 1$ \\
\hline
\end{tabular}

21 개의 모음들 중에서 각 그룹의 대표하는 $\mathrm{H} / \mathrm{H} / \mathrm{L} / \mathrm{T} /$ 1 들을 5 개의 버튼에 배치하고, 같은 계열의 모음들을 버튼 의 상하좌우로 확장하여 나타낼 경우 21 개의 모음들을 모두
배치할 수 있다. 추가적으로, 발음할 때에 입술을 둥글게 오 므려 소리를 내는 원순 모음인 $\perp / T$ 를 자음의 아래쪽에 배 치하고, 평순모음 $1 / / / / 1$ 를 자음의 오른쪽에 배치하는 구 조를 가지도록 하였다. 이럴 경우, 종성(받침) 없이 한글의 자음과 모음이 어울리는 모습을 보여주게 되어, 사용자의 직관성을 높일 수 있다. 7 개의 자음들을 순서대로 버튼의 왼쪽 위부터 배치하고, ㄴ/ㄱ/l 모음을 7 개 자음들의 오른 쪽에, 그리고 ㄴ/T 모음을 아래쪽에 배치하였다. Fig. 10에 서 보듯이, 가장 윗줄에 $ᄀ$ /느이 배치되어 있으므로 ' $S^{-}$가나' 자판이라고 한다.

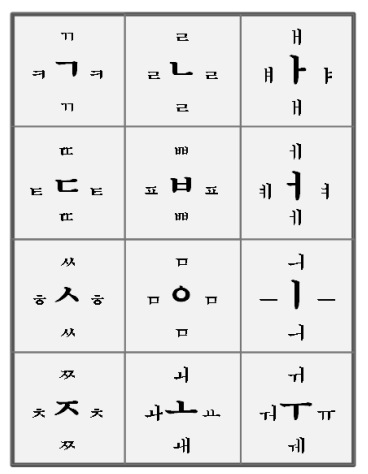

Fig. 10. s-Gana Korean Keypad

\section{$4.2 s-$ 바다 한글 자판}

한글은 자음과 모음을 조합하여 하나의 글자를 만드는 특 징을 가지고 있다. 그러므로 사용자들이 많이 사용하는 자 음과 모음을 서로 가까이 배치하면 손가락이 움직이는 거리 가 줄게 되고 입력 속도가 빨라지게 된다. 이를 위하여 $S^{-}$ 바다 자판은 자음과 모음의 사용빈도를 분석하였다.

'고려대학교 민족문화연구소'에서 펴낸 '한글 사용빈도의 분석'에서는 한글 $29,512,693$ 자에 대해 초성/중성/종성으로 나누어 각각의 빈도수를 제시하였다[10]. 본 논문에서는 이 를 기반으로 자음과 모음의 빈도수를 산출하였는데, 자음의 빈도수는 초성과 종성의 빈도수의 합으로 구하였으며, 'ㅅ'과 같이 겹자음일 경우에는 한 번에 입력할 수 없으므로 각각 의 자음을 1 회로 계산하였다. Table 4 는 자음과 모음의 빈 도수에서, 7 개 대표 자음 및 5개 대표 모음으로 분류하여, 각 자음 및 모음의 사용률과 함께 각 대표음의 사용률을 보 여주고 있다.

Table 4의 자음과 모음의 사용빈도를 바탕으로, 많이 사 용하는 대표 자음 $0 /$ ㄴ/ㅅ/ㄱㄱㄱㅘ 대표 모음 $1 / /$ 를 가운데 로 모아 서로 가깝게 배치하였다. 상대적으로 사용률이 적 은 빋ㄷ/제서, '즈는 '人'과 가까운 버튼에, 사용률이 가장 적은 '버은 가장 멀리 위치한 버튼에 배치하였다. 모음에서 도 사용률이 가장 높은 ' ' '를 'O'의 오른쪽에 배치하고, 그 다음 사용률이 높은 'ㄱ'를 가운데로, 사용빈도가 낮은 'ㄱ'를 가장 위쪽 버튼에 배치하였다. Fig. 11에서 보듯이, 가장 윗 줄에 빋ㅇㅇㅣ 배치되어 있으므로 ' $S^{-}$바다' 자판이라고 하며, 각 버튼들의 사용빈도는 Fig. 12 와 같다. 
Table 4. Usage Rate of Hangul Consonants and Vowels

\begin{tabular}{|c|c|c|c|c|c|c|c|}
\hline $\begin{array}{c}\text { 자음 } \\
\text { (Consonants) }\end{array}$ & $\begin{array}{l}\text { 사용빈도수 } \\
\text { (Frequency) }\end{array}$ & \multicolumn{2}{|c|}{$\begin{array}{c}\text { 사용률 } \\
\text { (Usage Rate) }\end{array}$} & $\begin{array}{c}\text { 모음 } \\
\text { (Vowels) }\end{array}$ & $\begin{array}{l}\text { 사용빈도수 } \\
\text { (Frequency) }\end{array}$ & \multicolumn{2}{|c|}{$\begin{array}{c}\text { 사용률 } \\
\text { (Usage Rate) }\end{array}$} \\
\hline$\neg$ & $5,317,560$ & $12.27 \%$ & \multirow{3}{*}{$13.16 \%$} & t & $6,446,206$ & $21.84 \%$ & \multirow{4}{*}{$27.16 \%$} \\
\hline$\Rightarrow$ & 151,206 & $0.35 \%$ & & H & $1,358,698$ & $4.60 \%$ & \\
\hline 77 & 234,283 & $0.54 \%$ & & k & 207,430 & $0.70 \%$ & \\
\hline ᄂ & $6,515,889$ & $15.03 \%$ & \multirow{2}{*}{$25.82 \%$} & 月 & 6,917 & $0.02 \%$ & \\
\hline ᄅ & $4,676,606$ & $10.79 \%$ & & -1 & $3,149,526$ & $10.67 \%$ & \multirow{4}{*}{$20.22 \%$} \\
\hline ᄃ & $2,765,259$ & $6.38 \%$ & \multirow{3}{*}{$7.94 \%$} & ㅔ & $1,278,351$ & $4.33 \%$ & \\
\hline$E$ & 429,463 & $0.99 \%$ & & F & $1,399,223$ & $4.74 \%$ & \\
\hline$\llbracket[$ & 245,448 & $0.57 \%$ & & \# & 141,583 & $0.48 \%$ & \\
\hline ㅂ & $1,752,365$ & $4.04 \%$ & \multirow{3}{*}{$5.05 \%$} & 工 & $2,892,577$ & $9.80 \%$ & \multirow{5}{*}{$13.89 \%$} \\
\hline 표 & 387,597 & $0.89 \%$ & & 표 & 297,720 & $1.01 \%$ & \\
\hline 부 & 53,449 & $0.12 \%$ & & 나 & 544,377 & $1.84 \%$ & \\
\hline 人 & $3,023,530$ & $6.98 \%$ & \multirow{3}{*}{$14.13 \%$} & 내 & 36,134 & $0.12 \%$ & \\
\hline$\overline{0}$ & $2,276,447$ & $5.25 \%$ & & 니 & 330,639 & $1.12 \%$ & \\
\hline 从 & 824,330 & $1.90 \%$ & & T & $2,020,380$ & $6.85 \%$ & \multirow{5}{*}{$8.59 \%$} \\
\hline 0 & $9,087,252$ & $20.97 \%$ & \multirow{2}{*}{$26.26 \%$} & $\pi$ & 156,578 & $0.53 \%$ & \\
\hline ㅁ & $2,293,480$ & $5.29 \%$ & & 꺼 & 187,423 & $0.64 \%$ & \\
\hline 下 & $2,544,016$ & $5.87 \%$ & \multirow{3}{*}{$7.63 \%$} & 게 & 7,757 & $0.03 \%$ & \\
\hline 天 & 698,837 & $1.61 \%$ & & T) & 159,691 & $0.54 \%$ & \\
\hline 不 & 66,049 & $0.15 \%$ & & 1 & 4,523,698 & $15.33 \%$ & \multirow{3}{*}{$30.13 \%$} \\
\hline & & & & - & $3,760,640$ & $12.74 \%$ & \\
\hline & & & & -1 & 607,145 & $2.06 \%$ & \\
\hline
\end{tabular}

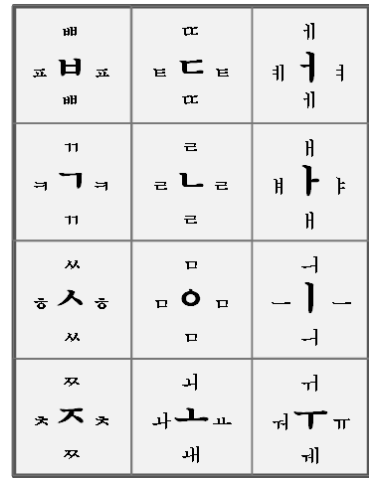

Fig. 11. s-Bada Hangul Keypad

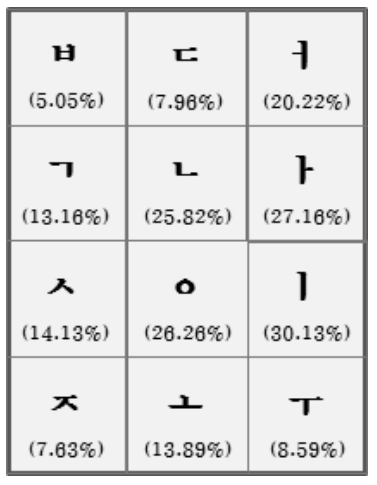

Fig. 12. usage rate of each button in $s$-Bada Keypad

\section{$4.3 s$-가나 및 $s$-바다 자판 비교}

$s^{-}$가나와 $s^{-}$바다 한글 자판을 끌기 기능이 추가된 $s^{-}$천 지인, $s^{-}$나랏글, $s-\mathrm{SKY}$ 자판들과 비교하기 위하여 3.2 절에 서 기술한 동일한 방식으로 실험을 진행하였다.

Fig. 13 은 애국가와 훈민정음을 5 개의 한글 자판에서 실 험한 결과를 보여준다. Fig. 13에서 아래의 진한 부분은 버 튼의 터치횟수이고, 위의 연한 부분은 손가락이 움직이는 이동 거리이다. 결과에서 보듯이, 모든 자판에서 예문을 입
력할 때의 터치횟수는 큰 차이가 없다. 다만 $S^{-}$천지인과 $S^{-}$ 나랏글 자판에서는 버튼에서 바로 지원하지 않는 모음을 입 력하기 위해서 2 번 이상 버튼을 터치해야하기 때문에 버튼 의 터치횟수가 많아지게 된다. 각 자판의 손가락 이동거리 는 자판에 따라 큰 차이를 보이고 있으며, $s^{-}$가나와 $s^{-}$바다 자판의 이동거리를 기준으로 다른 자판들의 이동거리와 비 교해보면 Table 5 와 같다.

Table 5. Distance Comparision of $s$-Keypads based on $s$-Gana and $s$-Bada

(a) Korean National Anthem

\begin{tabular}{|c|c|c|c|}
\hline $\begin{array}{c}\text { 성능 향상도 }(\%) \\
\text { Perf Improvement }\end{array}$ & $\begin{array}{c}s^{-} \text {천지인 } \\
(s \text {-Cheonjiin })\end{array}$ & $\begin{array}{c}s \text {-나랏글 } \\
(s \text {-Naragul })\end{array}$ & $\begin{array}{c}s \text {-SKY } \\
(s-S K Y)\end{array}$ \\
\hline$s^{-}$가나 ( $s^{-G a n a)}$ & 14.8 & -2.4 & 3.0 \\
\hline$s^{-}$바다 $(s$-Bada) & 22.9 & 7.3 & 12.2 \\
\hline
\end{tabular}

(b) Hunminjeongeum

\begin{tabular}{|c|c|c|c|}
\hline $\begin{array}{l}\text { 성능 향상도 (\%) } \\
\text { Perf Improvement }\end{array}$ & $\begin{array}{c}S \text {-천지인 } \\
(S-\text { Cheonjiin })\end{array}$ & $\begin{array}{c}S^{-} \text {나랏글 } \\
\text { (S-Naragul) }\end{array}$ & $\begin{array}{c}s^{-S K Y} \\
(s-S K Y)\end{array}$ \\
\hline$s^{-}$가나 (s-Gana) & 14.3 & -6.4 & 3.6 \\
\hline 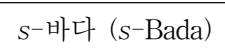 & 22.1 & 3.3 & 12.4 \\
\hline
\end{tabular}




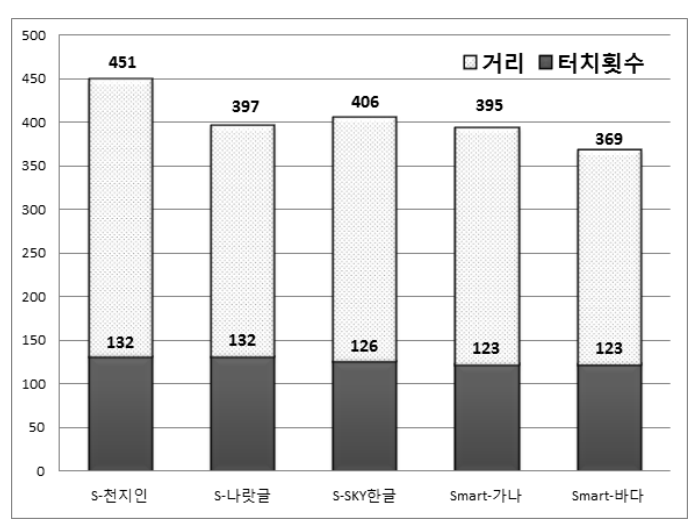

(a) Korean National Anthem

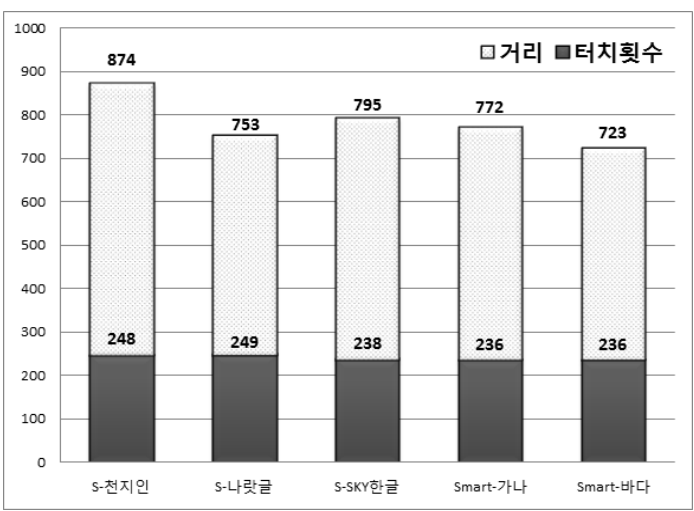

(b) Hunminjeongeum

Fig. 13. Performance Comparison of $s$-Keypads

Table 5에서 보듯이, $S^{-}$가나는 $S^{-}$천지인과 비교했을 때 뚜렷한 성능 향상을 보였지만, 그 외의 다른 자판들과 비교 했을 때는 성능 차이를 보이지 않고 있다. 그러나 $s^{-}$바다는 $S$-천지인과 비교했을 때 $20 \%$ 이상의 성능이 향상되었고, $S-S K Y$ 는 $10 \%$ 이상, $s^{-}$나랏글에서는 $3 \sim 7 \%$ 의 성능 향상을 보여주었다. 끌기 기능이 적용되면, 자음 및 모음들을 대부 분 터치 한번 혹은 터치와 끌기 한번으로 입력이 가능하게 되어, 모든 자판에서 한글을 손쉽게 입력할 수 있게 된다. 하지만 사용 빈도가 높은 자음과 모음을 효과적으로 배치하 면, 손가락의 이동거리가 최소화되고, 결국 빠른 입력이 가 능하게 된다. $S^{-}$바다 한글 자판은 자음과 모음의 사용빈도 를 고려하여 버튼을 배치하였으며, 따라서 다른 자판들과 비교하여 가장 좋은 성능을 보여주었다. 또한 끌기 기능이 적용되지 않은 기존의 표준 한글 자판들과 비교하면, 더욱 성능이 향상되는 것을 확인할 수 있다.

Table 6은 끌기 기능이 없는 기존의 3가지 표준 한글 입 력 자판과 끌기 기능을 적용시킨 $S^{-}$가나와 $S^{-}$바다 자판의 실험 결과를 비교한 것이다. $S^{-}$바다 한글 자판의 경우, 천지 인과 나랏글과 비교하여 $20 \%$ 이상, $\mathrm{SKY}$ 한글에서도 $10 \%$ 이상의 성능이 향상된 것을 확인할 수 있다.

Table 7은 본 논문의 서론에서 제시한 SELF-T의 요소들 을 평가기준으로 사용하여, 천지인, 나랏글, SKY한글, 밀기 글, 딩굴, $s^{-}$가나, $s^{-}$바다 한글 자판의 사용성을 평가하였다.
Table 6. Distance Comparison with 3 standard Korean Keypads

(a) Korean National Anthem

\begin{tabular}{|c|c|c|c|}
\hline $\begin{array}{c}\text { 성능 향상도 (\%) } \\
\text { Perf Improvement }\end{array}$ & $\begin{array}{c}\text { 천지인 } \\
\text { (Cheonjiin) }\end{array}$ & $\begin{array}{c}\text { 나랏글 } \\
\text { (Naragul) }\end{array}$ & SKY (SKY) \\
\hline$s^{-}$가나 (s-Gana) & 19.1 & 15.9 & 5.4 \\
\hline$s^{-}$바다 ( $s^{-}$-Bada) & 24.4 & 21.4 & 11.6 \\
\hline
\end{tabular}

(b) Hunminjeongeum

\begin{tabular}{|c|c|c|c|}
\hline $\begin{array}{c}\text { 성능 향상도 (\%) } \\
\text { Perf Improvement }\end{array}$ & $\begin{array}{c}\text { 천지인 } \\
\text { (Cheonjiin) }\end{array}$ & $\begin{array}{c}\text { 나랏글 } \\
\text { (Naragul) }\end{array}$ & $\begin{array}{c}\text { SKY한글 } \\
\text { (SKY) }\end{array}$ \\
\hline$s^{-}$가나 ( $s^{-}$-Gana) & 17.0 & 17.2 & 3.5 \\
\hline$s^{-}$바다 (s-Bada) & 22.2 & 22.4 & 9.6 \\
\hline
\end{tabular}

각 항목별 평가지준을 $1 \sim 5$ 점으로 (5점이 가장 좋음) 평가하 였다.

나랏글은 천지인과 SKY한글과 비교하였을 때, '획추가'와 '쌍자음' 버튼으로 직관성과 학습성이 떨어진다. 입력 속도는 천지인과 비교하여 조금 빠르지만, SKY한글과 비교하면 $10 \%$ 이상 느리다.

밀기글, 딩굴, $S^{-}$가나와 $S^{-}$바다 자판들은 모두 끌기 (dragging) 기능이라는 최신 기술이 적용되었으며, 이 기능

Table 7. Usability Evaluation of Korean Keypads

\begin{tabular}{|c|c|c|c|c|c|c|c|}
\hline 평가기준 (Criteria) & $\begin{array}{c}\text { 천지인 } \\
\text { (Cheonjiin) }\end{array}$ & $\begin{array}{c}\text { 나랏글 } \\
\text { (Naragul) }\end{array}$ & $\begin{array}{c}\text { SKY } \\
(\mathrm{SKY})\end{array}$ & $\begin{array}{c}\text { 밀기글 } \\
\text { (Milgigul) }\end{array}$ & $\begin{array}{c}\text { 딩굴 } \\
\text { (Dinggul) }\end{array}$ & $\begin{array}{c}S^{-} \text {가나 } \\
\left(s^{-G a n a}\right)\end{array}$ & $\begin{array}{c}S^{-} \text {바다 } \\
(s \text {-Bada) }\end{array}$ \\
\hline 단순성 (Simplicity) & 5 & 4 & 5 & 3 & 4 & 5 & 4 \\
\hline 오류성 (Errors) & 3 & 3 & 3 & 3 & 4 & 4 & 4 \\
\hline 학습성 (Learnability) & 5 & 3 & 4 & 3 & 4 & 5 & 5 \\
\hline 속도 및 효율성 (Fast) & 3 & 3 & 4 & 5 & 5 & 4 & 5 \\
\hline 최신기술 (Technology) & 3 & 3 & 3 & 5 & 5 & 5 & 5 \\
\hline
\end{tabular}


을 이용하면 터치만으로 입력하는 천지인, 나랏글, SKY한글 과 비교하여 입력 오류가 줄어든다. 하지만 밀기글의 경우 종성까지 한 번에 글자를 입력할 수 있기 때문에 오류가 일 어날 가능성이 많아지고, 익숙해진 후에는 빠르게 문자를 입력할 수 있지만 학습하는데 시간이 걸리는 단점이 있다.

$S^{-}$가나 자판은 7 개 자음과 모음이 순서대로 배치되어 단 순하고 사용자들에게 친숙하다. $S^{-}$바다 자판은 자음과 모음 의 사용빈도를 고려하여 배치하여, $S^{-}$가나와 비교하였을 때 단순성이 떨어지지만 문장의 입력 속도는 빠르다. 결론적으 로 끌기 기능을 적용할 수 있는 스마트폰에서 한글 자판들 을 SELF-T의 5가지 요소로 비교 평가하였을 때, $S^{-}$가나와 $S^{-}$바다가 가장 우수한 사용성을 보여준다.

\section{5. 결 론}

2011년 6월에 천지인, 나랏글, SKY한글, 3가지 자판 모두 국내 기업에서 제조된 모든 스마트폰에서 사용할 수 있는 표준으로 제정되었다. 세 가지 방식 모두 $4 \times 3$ 의 12 개 버튼 을 사용하고 있으며 멀티 터치를 기반으로 한글의 자음과 모음을 조합하여 입력하는 방식을 사용하고 있다. 하지만 한글 자판이 표준으로 제정되었음에도, 스마트폰을 위한 새 로운 한글 자판들이 계속해서 제안되고 있으며, 앱 마켓에 서도 스마트폰용 한글 자판을 위한 다양한 앱들을 쉽게 찾 아볼 수 있다. 하지만, 사용자들은 여전히 더욱 편리하고 빠 른 한글 자판을 요구하고 있다. 스마트폰에 적합한 최신의 기술(up-to-date Technology)이 적용되지 못하여 사용자들 은 여전히 만족하지 못하고 있는 것이다.

본 논문에서는 세가지 한글 표준 입력 자판에 끌기 기능 을 추가하여, 이들을 $s^{-}$천지인, $s^{-}$나랏글, 그리고 $s^{-S K Y}$ 라 고 하였다. 이 개선된 자판을 기존의 방식과 비교하여 입력 속도가 얼마나 향상되었는지를 실험으로 확인하였다. 개선 된 자판은 끌기 기능을 사용하므로 터치만으로 입력하는 기 존의 방식과 비교하여 문자를 입력할 때의 오류를 줄여줄 수 있으며, 표준으로 제정된 기존의 방식과 완벽한 호환성 을 가지고 있으므로, 기존의 사용자들도 그대로 기존의 한 글 자판처럼 사용할 수 있으며, 쉽게 끌기 기능을 사용할 수 있을 것이다.

또한 본 논문에서는 스마트폰을 위한 $S^{-}$가나와 $S^{-}$바다 한글 자판을 제안하였다. 두 한글 자판 모두 7 개의 자음과 5 개의 모음을 $4 \times 3$ 의 버튼에 배치하였으며, ㄱ/ㄱ//ㅣ모음을 자음의 오른쪽에, ㄴ/T 모음을 자음의 아래쪽에 배치하여 사용자들의 직관성을 높였다. 또한 21 개의 모든 모음들을 사용자가 바로 선택하거나 조합할 수 있도록 하였다. $S^{-}$가 나 한글 자판은 자음을 ㄱ/ㄴ/드눈으로 배치하여 사용자들 이 적은 학습시간만으로 쉽게 사용할 수 있다. $S^{-}$바다 한글 자판은 사용빈도가 높은 자음과 모음을 가운데로 가깝게 배 치하여 손가락이 움직이는 거리를 줄였으며, 따라서 한글을 빠르게 입력할 수 있다. 실험을 통하여 $S^{-}$바다 한글 자판의
성능을 기존의 방식과 비교하였으며, 실험 결과 천지인과 나랏글에서는 $20 \%$ 이상, SKY한글에서도 $10 \%$ 이상의 성능 이 향상되는 것을 확인하였다.

스마트폰에서 표준으로 제정된 3가지 한글 입력 자판 에 터치스크린의 끌기라는 새로운 기술(up-to-date Technology)을 적용하여, 한글 입력 속도(Fast)가 향상되는 것을 확인할 수 있었다. 또한 끌기 기능을 사용하면, 한글 입력이 더욱 단순해지고 (Simple), 오류가 적어지며 (Errors), 더욱 배우기 쉬어지는 (Learnability) 등, SELF의 4 가지 요소들을 모두 충족시킬 수 있다.

\section{참 고 문 헌}

[1] Sunghee Yeom, "Wire and Wireless subscriber statistics," Korea Communications Commission, 2012. 9.

[2] Korea Agency for Technology and Standards, "Arrangement of Korean character (Hangeul) on mobile information devices (KS X 5020)," Korea Standard Association, 2011. 6.

[3] Korea Communications Commission, "Arrangement of Korean Character (Hangeul) on Telephone (Korea Communications Standard KCS.KO-05.0046)," 2011. 6.

[4] J. Nielsen, R.L. Mack, "Usability Inspection Methods," John Wiley \& Sons, New York, 1994.

[5] Seung Kweon Hong, "Universal Design of Hangul Input Method for Mobile Phones," The Ergonomics Society of Korea. Vol.26, No.3, pp.117-124, 2007. 8.

[6] Milgigul, http://itvers.com.

[7] Dinggul, http://cafe.naver.com/dingulhangul.

[8] Gimoon Lee, Jinwoo Kim, Sangeok Lee, "Korean phonology (enlarged edition)," Hakyeon Press. 2000.

[9] Heunggyu Kim, "Analysis of the frequency of use of Hangul," Research Institute of Korean Studies, Korea University, 1997. 8.

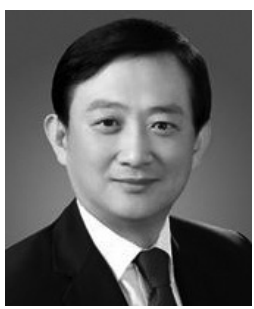

초 재 영 e-mail : choi@ssu.ac.kr 1984년 서울대학교 제어계측공학과(학사) 1986년 미국 남가주대학교 전기공학부 (공학석사) 1991년 미국 코넬대학교 전기공학과 (공학박사)

1992년 1994년 미국 국립 오크리지연구소 연구원 1994년 1995년 미국 테네시 주립대학교 연구교수 1995년 현 재 숭실대학교 컴퓨터학부 교수 관심분야: Distributed Computing, $\mathrm{HPC}$, System Software 


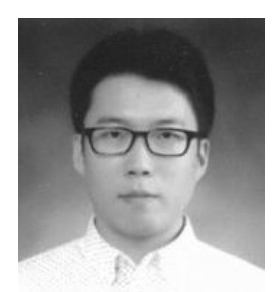

임 상 글

e-mail : sanggul@ssu.ac.kr

2007년 현 재 숭실대학교 컴퓨터학부 학사과정

관심분야: System Software, Distributed Computing, Artificial Intelligence

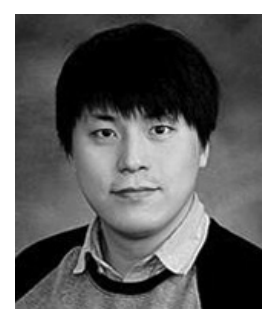

양 우 철

e-mail : moolmang@ssu.ac.kr

2007년 현 재 숭실대학교 컴퓨터학부 학사과정

관심분야: Embedded System, Database, System Software 